\title{
Copper Photoelectrodeposition onto Boron Doped Micro and Ultra-nanocrystalline Diamond Electrodes Applied to Nitrate Electroreduction
}

\author{
A. B. Couto, M. R. Baldan, N. G. Ferreira \\ Instituto Nacional de Pesquisas Espaciais, São José dos Campos, Brasil.
}

The influence of the boron doped micro and ultra-nanocrystalline diamond (BDD and BDUND) morphologies in the copper photoelectrodeposition was investigated. Copper particles were deposited in the potentiostat mode and under UV irradiation for both electrodes. For BDD, the copper deposits presented high density and uniformity all over the crystal faces. This behavior may be explained by its semiconductor character that promoted additional photogenerated electrons enhancing the copper reduction reaction. Otherwise, for BDUND the copper particles were randomly located with low density. Concerning the nitrate reduction process, $\mathrm{Cu} / \mathrm{BDD}$ presented a better response and reproducibility compared to those for the $\mathrm{Cu} / \mathrm{BDUND}$ electrode.

\section{Introduction}

Nitrate has been considered an important environmental contaminant of soil and natural waters (ground and surface water). This contamination is mainly due to the excessive use of nitrogen fertilizers in the soil, especially in rural and agricultural areas. Because of its high mobility, the irrigation process and the rain water are capable of carrying the nitrate not only on the surface but it also penetrates the soil, thus contaminating large areas. Consequently, many studies have appeared over the recent years in which researches attempt to convert nitrate into harmless nitrogen (1).

Nitrate electroreduction is one of the methods used to remove these ions from the polluted waters. Thus, the electrochemical process appears to be a clean, highly effective and inexpensive alternative technique (2). In this sense, boron doped diamond (BDD) has been reported to be an excellent electrode to study the nitrate reduction due to its outstanding electrochemical features such as: the wide potential window in aqueous solutions and the weak adsorption for most types of molecules $(3,4)$. For this purpose, the BDD performance may be improved by depositing copper particles on its surface, which are responsible for its sensitivity and selectivity increasing the nitrate electroreduction process (5).

Several studies have confirmed that the photo-assisted metal deposition method is very useful for the preparation of efficient electrode material $(6,7)$. Fujishima and Honda have argued that one of the most prominent features of semiconductors is their photoactivity (8). Among the semiconductors, the titanium dioxide has been widely exploited for its photochemical properties, like metal photodeposition and organic compound decomposition in contaminated waters $(9,10)$. Conversely, the diamond film has received less attention, especially with respect to the photoelectrodeposition of metallic ions on its surface.

The diamond, in its natural state, is considered a wide band gap semiconductor (5.5 eV). Due to its extremely wide gap and its conduction band edge is located at a very negative 
potential (-4.0 V versus SHE), the photogenerated electrons in diamond surface have extremely high reducing power. Nevertheless, after the boron doping, the BDD electrodes present the Fermi level at around $0.4 \mathrm{eV}$ from the top of the valence band and works as the boron acceptor level (11). So, the diamond serves as a source of electrons to reduce the ions to be deposited as well as a substrate for their deposition.

Thus, the aim of this work is to make a comparative study between the copper photoelectrodeposition onto boron doped microcrystalline diamond (BDD) and boron doped ultra-nanocrystalline diamond (BDUND). We discuss the influence of the morphology, the crystal size, the crystallographic orientation, and the surface termination in the reactivities of photogenerated electrons to understand the copper photocatalytic deposition in diamond films. Furthermore, the electrochemical response of these modified electrodes was studied for nitrate electroreduction.

\section{Experimental Procedure}

The films were grown by hot filament-assisted chemical vapor deposition (HFCVD) technique using the following growth parameters: $800{ }^{\circ} \mathrm{C}, 50$ Torr, $16 \mathrm{~h}$, gas mixture of $1 / 99 \%$ of the $\mathrm{CH}_{4} / \mathrm{H}_{2}$ for $\mathrm{BDD}$ and $650{ }^{\circ} \mathrm{C}$, 30 Torr $16 \mathrm{~h}$, gas mixture of $1 / 19 / 80 \%$ of the $\mathrm{CH}_{4} / \mathrm{H}_{2} / \mathrm{Ar}$ for BDUND. The films were deposited on the silicon substrate after seeding pre-treatment (12). The boron source was obtained by an additional hydrogen line passing through a bubbler containing $\mathrm{B}_{2} \mathrm{O}_{3}$ dissolved in methanol. The doping level corresponds to the acceptor densities of around $10^{21}$ atoms $\mathrm{cm}^{-3}$ estimated from Raman's measurements (not shown).

The electrochemical measurements were made using Autolab PGSTAT 302 equipment with a three-electrode cell. The geometric area of the diamond films in contact with the electrolyte was $0.13 \mathrm{~cm}^{2}$. A platinum mesh served as a counter electrode and $\mathrm{Ag} / \mathrm{AgCl} / \mathrm{KCl}_{\text {(sat) }}$ was used as the reference electrode. All electrode potentials in the text are referred to this electrode. The photoelectrodeposition of $\mathrm{Cu}$ particles on diamond films was performed in the potentiostatic mode, at a fixed potential of $-0.6 \mathrm{~V}$ for $10 \mathrm{~min}$, in a $1 \mathrm{mmol} \mathrm{L}^{-1} \mathrm{CuSO}_{4}, 50 \mathrm{mmol} \mathrm{L}^{-1} \mathrm{H}_{2} \mathrm{SO}_{4}$ aqueous solution, under UV irradiation. The light source was a home made system, composed of a set of five commercial lamps (Philips TUV $30 \mathrm{~W} / \mathrm{G} 30 \mathrm{~T} 8$ ) placed in a closed box. The UV irradiance at the electrode position was $12 \mathrm{~W} / \mathrm{m}^{2}$ measured by a radiometer. Before (30 $\mathrm{min}$ ) and during the photoelectrodeposition, the solution was purged with $\mathrm{N}_{2}$. The morphologies of the $\mathrm{Cu}$ modified diamond films were verified from the scanning electron microscopy (SEM) images using a Jeol JSM-5310 microscope. The nitrate reduction experiments were monitored by the linear sweep voltammetry using $0.01 \mathrm{~mol} \mathrm{~L}^{-1} \mathrm{KNO}_{3}+0.001 \mathrm{~mol} \mathrm{~L}^{-1}$ Britton-Robinson (BR) buffer $(\mathrm{pH}=3)$.

\section{Results and discussion}

Electrochemical responses of diamond films in the cooper electrodeposition

Firstly, a cyclic voltammetry at $100 \mathrm{mV} \mathrm{s}^{-1}$ was performed in order to characterize the $\mathrm{Cu}$ reduction and oxidation processes on the BDD and the BDUND surfaces. This procedure is important to choose the suitable potential to be applied during the photoelectrodeposition. Figure 1 shows cyclic voltammograms of $\mathrm{Cu}$ on BDD and BDUND films in a solution containing $1 \mathrm{mmol} \mathrm{L}^{-1} \mathrm{CuSO}_{4}+50 \mathrm{mmol} \mathrm{L}^{-1} \mathrm{H}_{2} \mathrm{SO}_{4}$. 


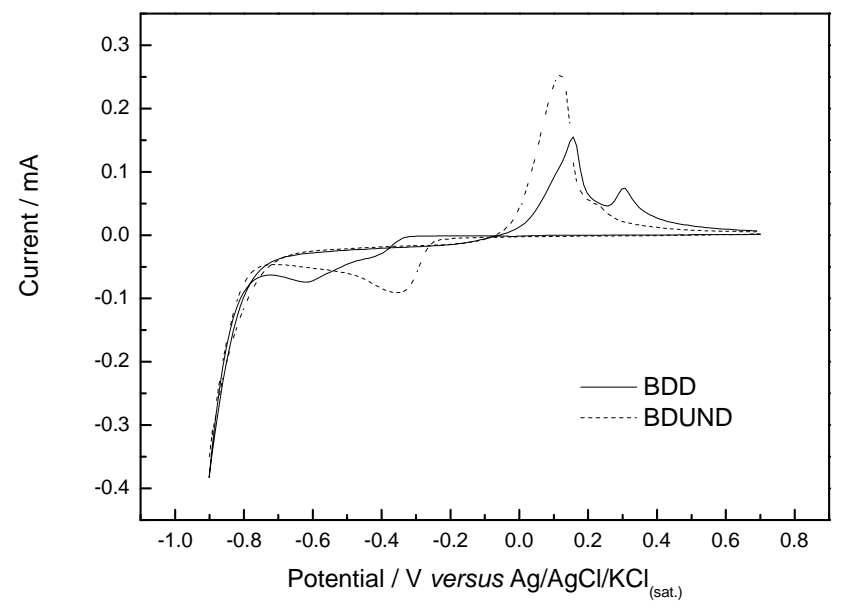

Figure 1. Cyclic voltammetry responses BDD and BDUND electrodes in solution of $50 \mathrm{mmol} \mathrm{L}^{-1} \mathrm{H}_{2} \mathrm{SO}_{4}$ support electrolyte containing $1 \mathrm{mmol} \mathrm{L}^{-1} \mathrm{CuSO}_{4}$.

The processes of deposition and dissolution are clear for both films. However, these results were influenced by the film morphologies. The potential sweeping started at $0.7 \mathrm{~V}$ and during the negative potential scan two $\mathrm{Cu}$ cathodic current peaks were observed for BDD electrode. The first cathodic current peak, at around $-0.4 \mathrm{~V}$, may be associated to the reduction of $\mathrm{Cu}^{2+}$ to $\mathrm{Cu}^{+}$ions. The second peak, at around $-0.6 \mathrm{~V}$, corresponds to the $\mathrm{Cu}^{+}$ions to the metallic $\mathrm{Cu}$ or directly from the $\mathrm{Cu}^{2+}$ ions to the metallic $\mathrm{Cu}$ reduction process. In the reverse potential scan, two crosses were observed according to those observed by Fletcher et al. (13). The more cathodic crossing at $-0.37 \mathrm{~V}$ is characterized as the nucleation $\left(E_{n}\right)$, whereas the second crossing at $-0.06 \mathrm{~V}$ indicates the reversible potential $\left(\mathrm{E}_{\mathrm{rev}}\right)$ of the $\mathrm{Cu}^{2+} / \mathrm{Cu}$ system. In more positive potentials, the appearance of two anodic current peaks at $0.15 \mathrm{~V}$ and at $0.30 \mathrm{~V}$ indicates the $\mathrm{Cu}$ dissolution corresponding to the different $\mathrm{Cu}$ phases deposited during the negative potential sweep. For the BDUND electrode, the behavior is a little different. During the scan toward negative potentials the cathodic current started to increase at around $-0.23 \mathrm{~V}$ indicating that the $\mathrm{Cu}$ deposition process began at this potential. The two Cu reduction processes were not clearly observed, as noted in the BDD electrode. This behavior may be attributed to a less favorable energy condition for the $\mathrm{Cu}^{2+}$ to $\mathrm{Cu}^{+}$ions reduction process on the BDUND. Leading the sweep reversal at $-0.9 \mathrm{~V}$, two crosses were also observed at -0.25 and $-0.08 \mathrm{~V}$, corresponding to the nucleation and the reversible potentials, respectively. In more positive potentials, the appearance of a peak current at $0.12 \mathrm{~V}$ indicates the bulk $\mathrm{Cu}$ stripping. Besides, this peak is followed by a slight shoulder of anodic current concerning a small amount of other electrodeposited $\mathrm{Cu}$ phases. Considering the $\mathrm{Cu}$ electrochemical process presented above, the optimum potential for the photoelectrodeposition was found at $-0.6 \mathrm{~V}$, which certainly permitted to control the deposits for both electrodes.

\section{$\underline{\text { Copper particles photoelectrodeposition and nitrate reduction }}$}

Figure 2 shows the SEM images of the diamond surface after the $\mathrm{Cu}$ photoelectrodeposition, where images (a) and (b) refer to the BDD and the BDUND film, respectively. Figure 2 shows the surface modification of $\mathrm{Cu}$ particles resulting in a morphology composed of rounded grains distributed throughout the surface of both films. 

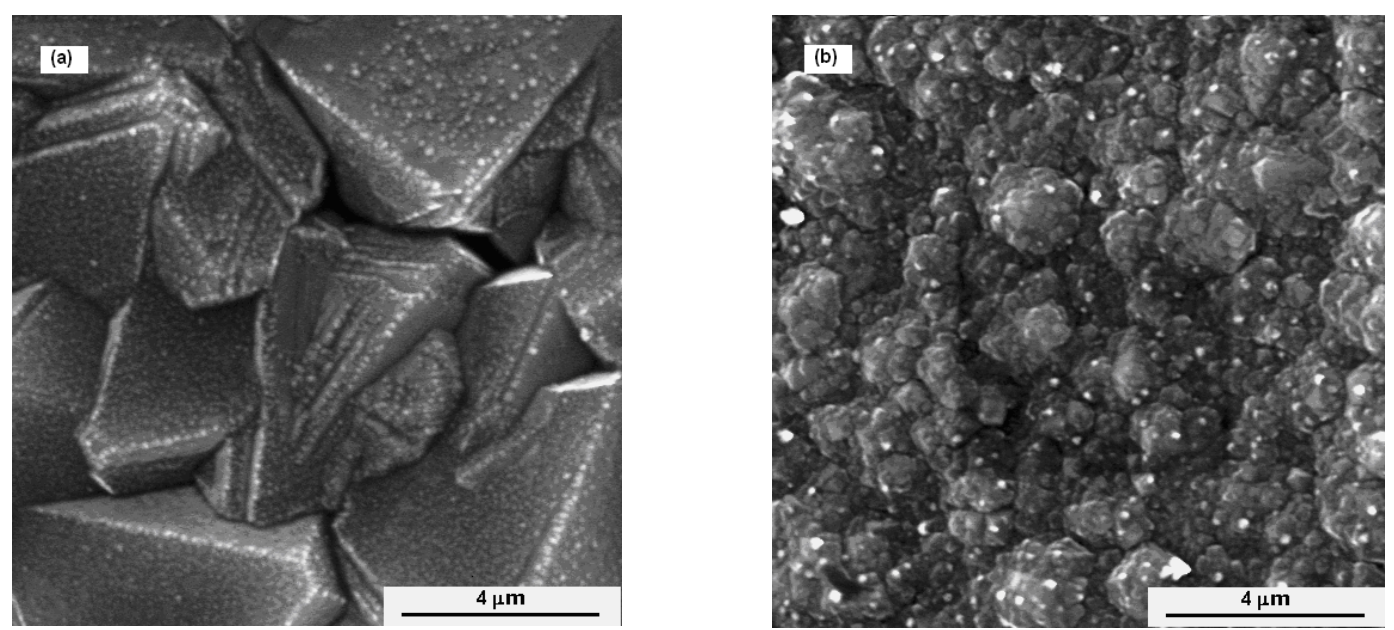

Figure 2. SEM images of BDD (a) and BDUND (b) electrodes after $\mathrm{Cu}$ particle photoelectrodeposits.

According to Figure 2 (a), the BDD exhibits the highest density and the best uniformness of $\mathrm{Cu}$ particles on the electrode surface. For the BDUND (image b) the electrodeposits seem larger and at the cluster grain boundaries of the BDUND. They are randomly located, with low particle density. The strong difference between the electrodeposits in both electrodes may be explained due to the semiconductor character of such films. Firstly, the BDD surface presents high diamond purity where the conductivity is due to the boron excess at the top of its valence band. So, the photoassisted process by UV irradiation generates additional electrons at the conduction band that may participate in the $\mathrm{Cu}$ electroreduction. In addition, the positive holes at the valence band may oxidize the water to molecular oxygen or hydroxyl radicals. Also, BDD represents a wide band gap semiconductor. This process is improved due to the large BDD band gap, where the recombination of the electrons is lower compared to that of conventional semiconductors (14). In this way, this excess of electrons enhanced the $\mathrm{Cu}$ deposition. The possible reactions that may occurs in this photoassisted process is summarized in Table 1.

Table 1- Possible reactions in the photocatalytic process of the diamond in $1 \mathrm{mmol} \mathrm{L}^{-1}$ $\mathrm{CuSO}_{4}+50 \mathrm{mmol} \mathrm{L}^{-1} \mathrm{H}_{2} \mathrm{SO}_{4}$ aqueous solution.

$$
\begin{aligned}
& \mathrm{CuSO}_{4} \rightarrow \mathrm{Cu}^{2+}+\mathrm{SO}_{4}{ }^{2-} \\
& \mathrm{H}_{2} \mathrm{SO}_{4} \rightarrow 2 \mathrm{H}^{+}+\mathrm{SO}_{4}^{2-} \\
& \mathrm{H}_{2} \mathrm{O} \rightarrow \mathrm{H}^{+}+\mathrm{OH}^{-} \\
& \mathrm{hv} \rightarrow \mathrm{h}^{+}+\mathrm{e}^{-} \\
& \mathrm{Cu}^{2+}+2 \mathrm{e}^{-} \rightarrow \mathrm{Cu} \\
& 2 \mathrm{H}^{+}+2 \mathrm{e}^{-} \rightarrow \mathrm{H}_{2} \\
& \mathrm{OH}^{-}+\mathrm{h}^{+} \rightarrow \cdot \mathrm{OH}
\end{aligned}
$$


In the case of the BDUND electrode, the possible reactions that occur in this process should be analyzing considering its amorphous semiconductor character. Due to the $\mathrm{sp}^{2}$ bonds presence, this disorder reduces the BDUND band gap by a band tailing with additional states, which improves its conductivity (15). In this case, the electron excess by the photoprocess also occurs. Nonetheless, for the BDUND a significant contribution to its conductivity is the effect of $\mathrm{sp}^{2}$ bonding indicated by the $\pi$ and $\pi *$ bands. For this reason, we believe that the recombination for BDUND is faster than that for the BDD electrode reducing the photoeffect contribution to of additional electrons involved in the $\mathrm{Cu}$ deposition. This behavior led to the lowest density of $\mathrm{Cu}$ deposits on BDUND surface.

These modified films were used to evaluate their performance to the nitrate reduction. Figure 3 presents linear sweep voltamograms in the presence of nitrate for as-grown and $\mathrm{Cu} /$ diamond films. For both electrodes, the cathodic currents for buffer BR are associated to water reduction. It is possible to observe that $\mathrm{Cu}$ deposited on diamond surface catalyse the electroreduction of nitrate for both electrodes. The nitrate electroreduction is a very complex process. Several products are possible depending on the experimental conditions such as $\mathrm{pH}$ and applied potential. In this work, only one cathodic peak is observed around $-1.25 \mathrm{~V}$ for both as-grown diamond films, suggesting that nitrate reduction to ammonia is taking place at this potential. The effect of $\mathrm{Cu}$ deposits on the diamond surface was more pronounced in the BDD than that for the BDUND due to the greatest amount of $\mathrm{Cu}$ on its surface.
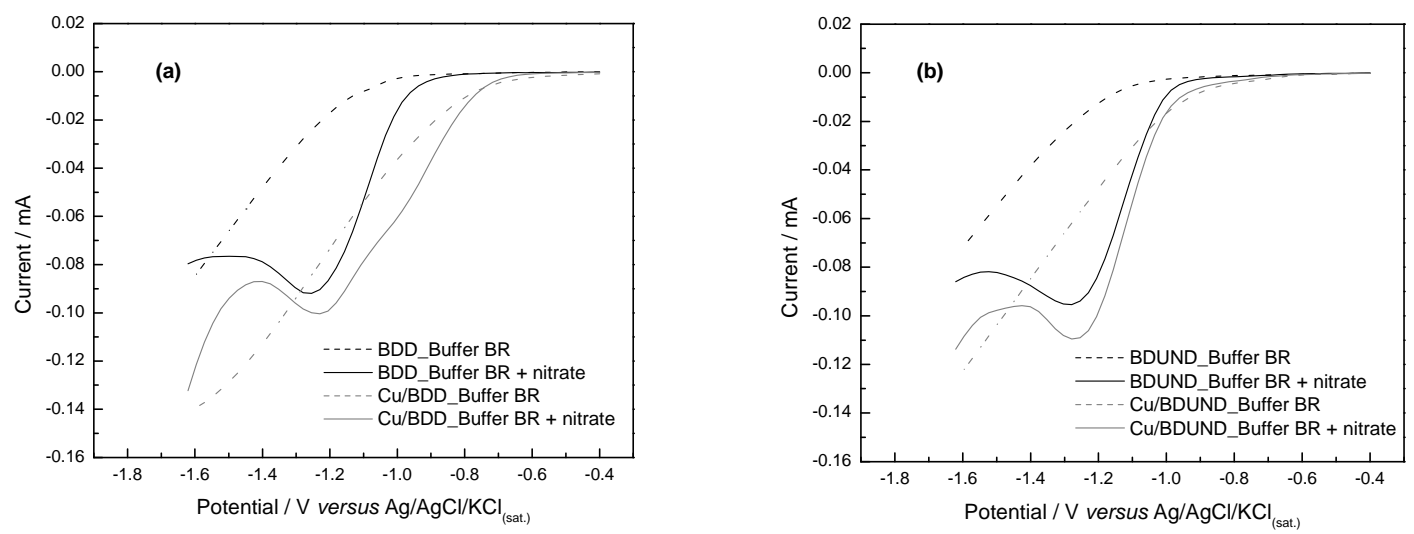

Figure 3. The response of diamond electrodes for $0.001 \mathrm{~mol} \mathrm{~L}^{-1} \mathrm{BR}$ buffer and for nitrate reduction in solution of $0.01 \mathrm{~mol} \mathrm{~L}^{-1} \mathrm{KNO}_{3}+0.001 \mathrm{~mol} \mathrm{~L}^{-1} \mathrm{BR}$ buffer. (a) BDD and (b) BDUND.

In Figure 3 (a), it is possible to observe the appearance of a slight new peak at around $-1.0 \mathrm{~V}$ associated to the nitrate reduction into hydroxylamine followed by the ammonia peak. These reduction processes were already observed by Aouina et al for the electroreduction of nitrate at a copper electrode in neutral solution (16). In addition, the stability of $\mathrm{Cu}$ particles on these films was evaluated from successive linear sweep voltammetry measurements for the nitrate reduction, shown in Figure 4 (a) and (b) for $\mathrm{Cu} / \mathrm{BDD}$ and $\mathrm{Cu} / \mathrm{BDUND}$, respectively. 

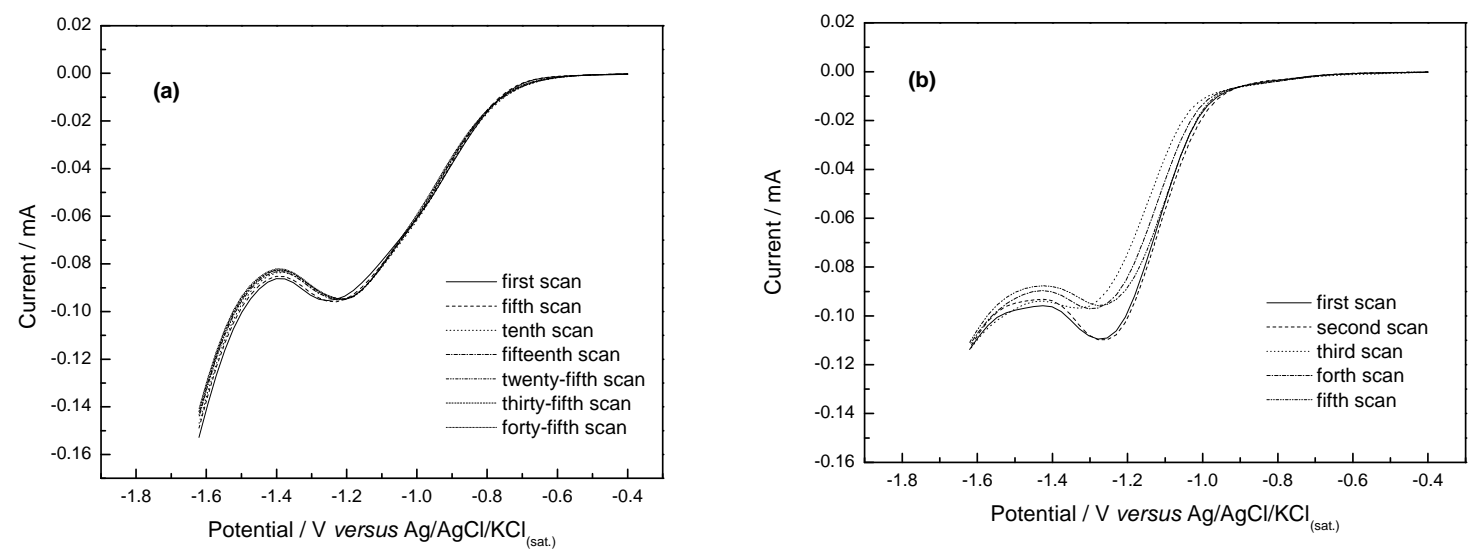

Figure 4. Subsequent scans of (a) $\mathrm{Cu} / \mathrm{BDD}$ and (b) $\mathrm{Cu} / \mathrm{BDUND}$ electrodes for $0.001 \mathrm{~mol} \mathrm{~L}^{-1} \mathrm{BR}$ buffer and for nitrate reduction in solution of $0.01 \mathrm{~mol} \mathrm{~L}^{-1} \mathrm{KNO}_{3}+$ $0.001 \mathrm{~mol} \mathrm{~L}^{-1} \mathrm{BR}$ buffer.

In the subsequent scans of nitrate reduction, the cathodic peak current decreased in the third measurement for $\mathrm{Cu} / \mathrm{BDUND}$ film, indicating that all $\mathrm{Cu}$ photoeletrodeposited came out of the BDUND surface. It is noted that from the third scan, the nitrate reduction response was the same for the as-grown BDUND electrode. Conversely, for the Cu/BDD electrode the reproducibility was evident, indicating that the copper particles were consolidated in the electrode surface. This behavior can be explained by the $\mathrm{Cu}$ particle deposition on the diamond faces while, for the BDUND, a suitable deposit on its surface was not obtained in order to assure the $\mathrm{Cu}$ particles consolidation.

This study showed that the copper photoelectrodeposition process on semiconducting diamond surface can be a good alternative for the preparation of modified electrode. By applying UV irradiation, the copper photoelectrodeposition and its consolidation were more efficient on the BDD than those on the BDUND electrode.

\section{Acknowledgments}

The authors are very grateful to FAPESP (Process 2010/05391-0), CAPES and CNPq for the financial support. Special thanks to Eduardo Saito and Fernando Almeida de Souza for providing the diamond samples.

\section{References}

1. S. Ghafari, M. Hasan, M.K. Aroua, Bioresource Technology, 99, 3965-3974 (2008). 2. M. Li, C. Feng, Z. Zhang, S. Yang, N. Sugiura, Bioresource Technology, 101, 6553-6557 (2010).

3. A.N. Ndao, F. Zenia, A. Deneuville, M. Bernard, C. Lévy-Clément, Diamond and Related Materials, 9, 1175-1180 (2000).

4. C. Lévy-Clément, N.A. Ndao, A. Katty, M. Bernard, A. Deneuville, C. Comninellis, A. Fujishima, Diamond and Related Materials, 12, 606-612 (2003). 
5. C.M. Welch, M.E. Hyde, C.E. Banks e R.G. Compton, Analytical Sciences, 21, 1421-1430 (2005).

6. T. Wu, Y. Li, Handbook of photochemistry and photobiology, p. 249, American Scientific Publishers, Japan, (2003).

7. S. Yoshihara, K. Shinozaki, T. Shirakashi, K. Hashimoto, D.A. Tryk, A. Fujishima, Electrochimica Acta, 44, 2711-2719 (1999).

8. A. Fujishima, K. Honda, Nature, 238, 37-38 (1972).

9. D.F. Ollis, E. Pelizetti, N. Serpone, Environ. Sci. Technol., 25, 1523-1529 (1991). 10. T. Kanki, H. Yoneda, N. Sano, A. Toyoda, C. Nagai, Chemical Engineering Journal, 97, 77-81 (2004).

11. P. Muret, C. Saby, Semicond. Sci. Technol., 19, 1-7 (2004).

12. R.C. Mendes de Barros, E.J. Corat, N.G. Ferreira, T.M. Souza, V.J. Trava-Airoldi, N.F. Leite, K. Iha, Diamond Related Materials, 5, 1323-1332 (1996).

13. S. Fletcher, C.S. Halliday, D. Gates, M. Westcott, T. Lwin, G.J. Nelson, Electroanalytical Chemistry, 159, 267-285 (1993).

14. Y.L. Zhong, A. Midya, Z. Ng, Z. Chen, M. Daenen, M. Nesladek, K.P. Loh, J. Am. Chem. Soc., 130, 17218-17219 (2008).

15. O.A. Williams, M. Nesladek, M. Daenen, S. Michaelson, A. Hoffman, E. Osawa, K. Haenen, R.B. Jackman, Diamond and Related Materials ,17, 1080-1088 (2008). 16. N. Aouina, H. Cachet, C. Debiemme-Chouvy, T.T.M. Tran, Electrochimica Acta, 55, 7341-7345 (2010). 